\title{
Title: Transitional B Cell Cytokines Predict Renal Allograft Outcomes
}

Authors: Aravind Cherukuri, PhD MRCP ${ }^{1,2}$; Alan D. Salama, PhD FRCP ${ }^{3}$; Rajil Mehta, MD ${ }^{1,2}$; Kanishka Mohib, $\mathrm{PhD}^{1}$; Leting Zheng, $\mathrm{MD}^{1,4}$; Ciara Magee, MRCP ${ }^{3}$; Mark Harber, FRCP ${ }^{3}$; Hans Stauss, FRCS ${ }^{5}$; Richard J. Baker, PhD FRCP ${ }^{6}$; Amit Tevar, MD ${ }^{1}$; Douglas Landsittel, PhD ${ }^{1,7}$; Fadi G. Lakkis, MD ${ }^{1,2,8}$; Sundaram Hariharan, MD ${ }^{1,2}$; David M. Rothstein, MD $^{1,2,8, \odot}$.

\section{Affiliations:}

1. Thomas E. Starzl Transplantation Institute, Department of Surgery, University of Pittsburgh, Pittsburgh, PA, 15261, USA

2. Renal and Electrolyte Division, Department of Medicine, University of Pittsburgh, Pittsburgh, PA, 15261, USA

3. University College of London Department of Renal Medicine, Royal Free Hospital, London, NW3 2QG, UK

4. Department of Rheumatology and Immunology, The First Affiliated Hospital of Guangxi Medical University, Nanning, Guangxi, 530021, China

5. UCL Institute of Immunity and Transplantation, Royal Free Hospital, London, NW3 2QG, UK

6. Renal Unit, St. James's University Hospital, Leeds, LS9 7TF, UK

7. Department of Biomedical Informatics, University of Pittsburgh, Pittsburgh, PA, 15206, USA

8. Department of Immunology, University of Pittsburgh, Pittsburgh, PA, 15213, USA

(C) Corresponding Author 


\section{Corresponding Author:}

Dr. David Rothstein, MD

200 Lothrop Street, Biomedical Science Tower, W1542

Pittsburgh, PA 15261

Email: rothsteind@upmc.edu Tel: 412-648-7154

\section{One Sentence Summary:}

A low transitional-1 B cell IL-10/TNF $\alpha$ ratio predicts rejection and supports pre-emptive intervention for patients following kidney transplantation. 


\begin{abstract}
:
Early immunological biomarkers that predict rejection and chronic allograft loss are needed to inform pre-emptive therapy and improve long-term outcomes. Here, we prospectively examined the ratio of interleukin (IL)-10 to tumor necrosis factor alpha (TNF $\alpha$ ) produced by transitional-1 B cells (T1B) at 3 months post-transplantation as a predictive biomarker for clinical and subclinical renal allograft rejection and subsequent clinical course. In both Training $(n=162)$ and Internal Validation $(\mathrm{n}=82)$ Sets, the T1B IL-10/TNF $\alpha$ ratio at 3 months post-transplantation predicted both clinical and subclinical rejection anytime in the first year. The biomarker also predicted subsequent late rejection with a lead time averaging 8 months. Amongst biomarker high-risk patients, $60 \%$ had early rejection, of which $48 \%$ recurred later in the first posttransplant year. Amongst high-risk patients without early rejection, 74\% developed late rejection. In contrast, only 5\% of low-risk patients had early and 5\% late rejection. The biomarker also predicted rejection in an External Validation Set $(n=95)$, and in key patient subgroups, confirming generalizability. Importantly, biomarker high-risk patients exhibited progressively worse renal function and decreased five year graft survival compared to low-risk patients. Treatment of B cells with anti-TNF $\alpha$ in vitro augmented the IL-10/TNF $\alpha$ ratio, restored regulatory activity, and inhibited plasmablast differentiation. To conclude, the T1B IL-10/TNF $\alpha$ ratio was validated as a strong predictive biomarker of renal allograft outcomes and provides a rationale for pre-emptive therapeutic intervention with TNF-blockade.
\end{abstract}




\section{Introduction:}

Despite remarkable short-term renal transplant outcomes, approximately $35 \%$ of recipients lose their allograft by 10 years, and this has changed little with time(1). Such late allograft loss is increasingly attributed to the cumulative effects of underlying sub-acute immunological injury discovered only after irreversible damage has already occurred(2,3). In this regard, up to $30 \%$ of surveillance biopsies in the first post-transplant year show subclinical rejection (SCR)(4-6). This suggests that although current immunosuppression reduces acute clinical rejection (ACR), it does not always prevent more subtle immune-mediated damage that can smolder unrecognized. Thus, there is a major interest in identifying high-risk patients far enough in advance to allow preemptive treatment before the effector alloimmune response has fully matured and irreversible damage has begun to occur.

Currently used clinical and laboratory parameters, including delayed graft function (DGF), serum creatinine, and donor specific antibody (DSA), are associated with worse outcomes but have limited predictive value $(7,8)$. Though frequent surveillance biopsies might identify patients with acute rejection, they are invasive and impractical(6). Moreover, they cannot identify individuals at high-risk for future rejection or those whose rejection may be refractory to therapy. Thus, there is an imminent need for non-invasive biomarkers to not just identify, but predict, future rejection and poor long-term outcomes. Various transcriptional profiles and protein signatures in peripheral blood or urine correlate with the diagnosis of rejection, but their ability to predict future rejection or long-term outcomes was unclear (9-12). Although transcriptional profiles were recently reported to predict rejection and long-term outcomes, their performance was not assessed in key patient subgroups (including immunosuppressive regimen, medication adherence, opportunistic viral infections, DGF and DSA), limiting their generalizability (9, 13- 
15). Importantly, these studies did not provide mechanistic insights that might guide therapeutic intervention.

B cells with regulatory activity (Bregs) have been implicated in modulating the immune response in alloimmunity, autoimmunity, and infectious immunity in both humans and mice (16-21). However, there are no specific markers for Bregs. We previously showed that human regulatory B cell activity is best defined by the ratio of interleukin (IL)-10 to tumor necrosis factor alpha $(\mathrm{TNF} \alpha)$ expression by immature (transitional) $\mathrm{B}$ cells, and that this ratio falls with late rejection(22, 23). Here, we conducted a prospective, multicenter observational study to determine whether the ratio of IL-10/TNF $\alpha$ expression by the transitional-1 B (T1B) subset, a marker of regulatory B cells in the peripheral blood, is an early predictor of acute rejection and clinical course in adult renal transplant recipients. Further, we studied the effect of TNFblockade on B cell regulatory activity to provide a rationale for personalized therapeutic intervention.

\section{Results:}

\section{University of Pittsburgh Medical Center (UPMC) allograft outcomes}

We first assessed clinical outcomes in all patients receiving transplants at UPMC between 2013 and $2015(\mathrm{n}=596)$. When not medically contraindicated, patients underwent two surveillance biopsies at 3 and 12 months in addition to for-cause biopsies. $21 \%$ of patients had no biopsies in the first year. In the remaining 468 patients, 28\% (n=138) had one biopsy and 72\% (n=330) had paired early and late biopsies. In these 468 patients, clinical $\mathrm{T}$ cell-mediated rejection (cTCMR) was diagnosed in $16.9 \%$ in the first year, and surveillance biopsies identified an additional $18.8 \%$ of patients with subclinical T cell-mediated rejection (scTCMR) (Fig. 1A). Overall, 3\% had mixed antibody-mediated rejection (ABMR) and TCMR, and none had pure ABMR. TCMR in 
the first year was associated with a similar decrease in five-year graft survival whether analyzed in all 596 patients transplanted between 2013 and 2015, or only in the 468 patients who had at least one biopsy (fig. S1).

The availability of paired biopsies (early and late, $n=330$ ) allowed us to analyze TCMR progression in the first year (Fig. 1A). Of these 330 patients, 25\% had "early" TCMR (0-4mos), of which more than half (14\%) was subclinical (Fig. 1B). Despite treatment, 44\% of those with early TCMR had recurrent or recalcitrant "late" TCMR (5-12mos). Of the patients without early TCMR (75\%), 23\% developed de novo late TCMR. Overall, 28\% (94/330 patients) had late TCMR, of which 70\% (66/94) was classified as subclinical (scTCMR). In this cohort with paired biopsies, any TCMR in the first year was associated with worse graft survival at 5 years (Fig. 1C). Notably, patients with early TCMR that resolved with therapy did not have worse outcomes than patients with no TCMR ( $\mathrm{p}=0.07$, Fig. 1D). In contrast, those with late TCMR, either recurrent or recalcitrant TCMR or de novo TCMR, had significantly worse graft survival, identifying patients with late TCMR as a high-risk group $(\mathrm{p}<0.001)$. Both late scTCMR and cTCMR were associated with decreased graft survival $(\mathrm{p}=0.01$ and $\mathrm{p}<0.001$, respectively, Fig. 1E). Thus, we aimed to identify a biomarker that not only predicts any rejection in the first year, but specifically predicts late rejection and long-term graft outcomes.

Biomarker study population: Of the 468 patients transplanted between 2013-2015 and had at least one biopsy, 244 participated in the UPMC biorepository. All were included in the biomarker study (162 in the Training Set, 82 in the Validation Set; Fig. 2). The breakdown of biopsies by timing and type is depicted in Fig. 2. Key characteristics of study participants and nonparticipants were similar except for higher live donor frequency and associated shorter cold 
ischemia time amongst study participants (table S1) Importantly, TCMR rates, both clinical and subclinical, were comparable.

\section{T1B IL-10/TNF $\alpha$ ratio and TCMR:}

To determine whether peripheral blood B cell subsets or the ratio of IL-10 to TNF $\alpha$ expressed by these B cells could predict TCMR, we asked whether they differed in patients with and without TCMR in the Training Set (fig. S2A). Patients with TCMR had a significantly lower frequency of transitional B $(\operatorname{TrB})(\mathrm{p}<0.001)$ and $\mathrm{T} 1$ transitional B $(\mathrm{T} 1 \mathrm{~B})$ cells $(\mathrm{p}<0.001)$ than patients without rejection at all time points (fig. S2A). This difference was largest at 3 and 6 months posttransplant and decreased at 12 months. We next analyzed the ratio of IL-10/TNF $\alpha$ expression by B cell subsets as a measure of pro- vs. anti-inflammatory cytokine polarization(22). The IL10/TNF $\alpha$ ratio within total $\mathrm{B}(\mathrm{p}=0.01), \operatorname{Tr} \mathrm{B}(\mathrm{p}<0.001)$ and T1B cells $(\mathrm{p}<0.001)$ in patients with TCMR was significantly lower and relatively stable at all time points in the first year (fig. S2B). The difference in the IL-10/TNF $\alpha$ ratio was largest in the TrB and T1B subsets and was maximal at 3 months (fig. S3A). This was also the earliest time point for complete B cell reconstitution after Thymoglobulin induction. Since we aimed to develop an early predictive biomarker that could allow for potential therapeutic intervention, we used the 3-month time point for additional analysis. In a logistic regression model of B cell subsets and their cytokine ratio assessed at 3 months, the T1B IL-10/TNF $\alpha$ ratio had the strongest predictive value for rejection and this was confirmed in an independent internal validation cohort (table S2, fig. S3B). Therefore, the T1B IL-10/TNF $\alpha$ ratio at 3 months was further examined as a biomarker.

The T1B IL-10/TNF $\alpha$ ratio was comparable between patients with cTCMR and scTCMR and with various grades of rejection in the Training Set (fig. S4A and B) and Internal Validation Set (fig. S4C and D). In the Training Set, a $71 \%$ reduction in the odds of TCMR (OR, 0.29; 
$\mathrm{p}<0.001$ ) was observed with every unit (integer) increase in the T1B IL-10/TNF $\alpha$ ratio (table S2). This translated to a ROC-AUC of 0.89 (95\% CI $0.83-0.95, \mathrm{p}<0.001)$ for prediction of TCMR in the first year (Fig. 3A). At an optimal cut-off value of 1.3 for the ratio, sensitivity was $86 \%$, specificity was $86 \%$, and negative predictive value (NPV) was $92 \%$. Fig. S5 shows TCMR rates at various cut-offs in the Training Set. Precision-recall curve (PRC) analysis revealed a positive predictive value (PPV) of $80 \%$ at $86 \%$ sensitivity (fig. S6A). Furthermore, the T1B IL10/TNF $\alpha$ ratio predicted scTCMR with similarly high sensitivity, specificity, NPV, and PPV, suggesting utility in guiding surveillance biopsies (Fig. 3B, fig. S6B). Moreover, the T1B IL10/TNF $\alpha$ ratio at 3 months predicted all late TCMR (recurrent or recalcitrant and de novo) (ROC-AUC, 0.83) (Fig. 3C, fig. S6C). In patients without early TCMR, the ratio predicted late de novo TCMR with a ROC-AUC of 0.90 (Fig. 3D, fig. S6D). Thus, the T1B IL-10/TNFa ratio is a strong predictor of overall TCMR and late TCMR in the first post-transplant year. Importantly, the T1B IL-10/TNF $\alpha$ ratio predicted late TCMR with an average lead time of $8.0 \pm$ 2.3 months.

The T1B IL-10/TNF $\alpha$ ratio was then validated in the Internal Validation Set (ROC-AUC, 0.92; 95\% CI, 0.86-0.89; p<0.001) (Fig. 3E). At the cut-off of 1.3 determined in the Training Set, it predicted TCMR in the first year with sensitivity of $86 \%$, specificity of $91 \%$, NPV of $91 \%$, and PPV of $86 \%$ (fig. S6E). Once again, the T1B IL-10/TNF $\alpha$ ratio at 3 months strongly predicted scTCMR (ROC-AUC, 0.92; 95\% CI, 0.85-0.99; p<0.001) (Fig. 3F, fig. S6F), all late TCMR (ROC-AUC of 0.82; p<0.001), and de novo late TCMR (ROC-AUC, 0.85;p<0.001) (Fig. 3G and H, fig. S6G and H).

When the Training and Internal Validation Sets were combined $(n=244)$, the T1B IL-10/TNF $\alpha$ ratio identified three distinct risk categories: high-risk (ratio 0-1.3; 83\% TCMR incidence); 
intermediate risk (ratio 1.31-1.6; 18\% TCMR incidence); and low-risk (ratio >1.6; 6.5\% TCMR incidence) (Fig. 4A). Next, we examined all 174 patients who underwent both early (0-4mos) and late (5-12mos) biopsies to analyze TCMR progression in these risk groups. As shown in Fig. 4B, 44\% (77/174) of patients were high-risk, 10\% (18/174) intermediate-risk, and the remaining $46 \%$ (79/174) low-risk. In the high-risk group, $60 \%$ had early TCMR at the time of biomarker evaluation and, despite anti-rejection therapy, $48 \%$ developed recurrent or recalcitrant late TCMR. In high-risk patients who did not have early TCMR, 74\% subsequently developed de novo late TCMR. Overall, 58\% of patients in the high-risk group had late rejection. In contrast, only 5\% of low-risk patients had early and 5\% had late TCMR. The incidence of TCMR in the intermediate risk category, comprising only $10 \%$ of the patients, was $6 \%$ (early) and 17\% (late). Thus, the T1B IL-10/TNF $\alpha$ ratio not only identified patients with markedly high rates of early TCMR, but also those with late TCMR, whether recurrent or recalcitrant TCMR or de novo TCMR. In comparison, histological diagnosis of early rejection alone was poorly predictive of subsequent rejection since $55 \%$ of all early rejections resolved and $56 \%$ of all late rejections were de novo (Fig. 4B).

External validation: The T1B IL-10/TNF $\alpha$ ratio as a marker for TCMR in the first year was further validated in an independent external cohort of 95 kidney allograft recipients at Royal Free Hospital, London. Unlike the UPMC cohorts, these patients received induction with Basiliximab and only underwent for-cause biopsies. Demographic characteristics are summarized in table S3. Again, TCMR within the first post-transplant year was associated with a significantly lower T1B IL-10/TNF $\alpha$ ratio compared to those without TCMR ( $<<0.001$, fig. S7). An increased ratio was associated with significantly reduced odds of TCMR (OR, 0.15; 95\% CI, 0.06-0.41; $\mathrm{p}<0.001)$. This translated into a ROC-AUC of $0.92(\mathrm{p}<0.001)$ for prediction of TCMR (Fig. 5A-B). At the 
cut-off value of 1.3 for the ratio, determined in the Training Set, Sensitivity was $75 \%$, specificity was $92 \%$, PPV was $67 \%$, and NPV was $4 \%$. Again, the T1B IL-10/TNF $\alpha$ ratio at 3 months predicted late TCMR with a ROC-AUC of 0.88 (95\% CI: 0.74-1.00, p=0.001) (Fig. 5C-D). Because protocol biopsies were not performed in this cohort, we were not able to assess either early or late scTCMR. None of the late cTCMRs were recurrent. Thus, the biomarker performed equally well in this distinct patient population that received different immunosuppression and only underwent for-cause biopsies.

To eliminate bias resulting from rejection episodes that occurred prior to the biomarker determination at 3 months (range 61-120 days), we re-analyzed the T1B IL-10/TNF $\alpha$ ratio excluding patients who had TCMR prior to biomarker determination. In the Training Set, the T1B IL-10/TNF $\alpha$ ratio predicted TCMR that occurred either concomitant with or after the determination of the biomarker with a ROC-AUC of 0.89 (95\% CI $0.83-0.96, \mathrm{p}<0.001$ ). At the cut-off value for the cytokine ratio of 1.3 , the sensitivity was $89 \%$, specificity was $85 \%$, PPV was 76\%, and NPV was 93\% (fig. S8A). Similarly, in both the Internal and External Validation Sets, the T1B cytokine ratio strongly predicted TCMR in the first post-transplant year even when patients with TCMR diagnosed prior to biomarker determination were excluded (fig. S8 B and C).

Stratified analysis: Once the biomarker was validated, we combined all three patient cohorts to assess its performance in patients stratified by key demographic and clinical variables. As shown in Fig. 6, the ratio was associated with a similarly low OR regardless of recipient age, gender, ethnicity, donor source, HLA mismatches, type of induction immunosuppression, DGF, serum creatinine at 3 months, or adherence to immunosuppression. Furthermore, the ratio predicted TCMR in all subgroups, with ROC-AUC's ranging from 0.87 to 0.94 (Fig. 6). Although patients 
with DSA in the first year had a lower ratio than those without DSA, the biomarker performed equally well in both groups (Fig. 6 and fig. S9). Finally, the ratio was not influenced by either cytomegalovirus (CMV) or BK virus (BKV) infection (Fig. 6 and fig. S10). Thus, the T1B IL10/TNF $\alpha$ ratio predicted TCMR in key patient subgroups, confirming generalizability.

To assess reproducibility, two trained lab personnel using the same experimental protocol, independently performed assays to determine the IL-10/TNF $\alpha$ ratio in samples from 8 healthy donors, starting with separate frozen aliquots of peripheral blood mononuclear cells (PBMCs) through flow cytometric analysis. The mean coefficient of variation (CV) between these personnel was $12.6 \%$ (fig. S11A). Further, the CV for T1B IL-10/TNF $\alpha$ ratio determined by the same individual on two different days $(n=6)$ was $3.8 \%$ (fig. S11B). Thus, both inter-personal and intra-personal variability in evaluating the IL-10/TNF $\alpha$ ratio were relatively low.

Long-term allograft outcomes: Our ultimate goal was to develop an early biomarker that risk stratifies patients for long-term allograft outcomes. Analysis of one-year biopsies in the UPMC cohorts revealed an increase in chronic damage manifest as interstitial fibrosis and tubular atrophy (IFTA) in high-risk (ratio $\leq 1.3$ ) compared to low-risk (ratio >1.6) patients (fig. S12). Renal function, assessed by estimated glomerular filtration rate (eGFR), progressively declined in high-risk compared to low-risk patients in both the UPMC $(\mathrm{p}=0.003)$ and the London $(\mathrm{p}=0.01)$ cohorts between 3 months and 4 years post-transplantation (Fig. 7A-B). Importantly, high-risk patients had significantly worse 5-year overall and death-censored graft survival compared to low-risk patients ( $\mathrm{p}<0.001$, Fig. 7C-E; p=0.001, Fig. 7F). Further, a composite endpoint of allograft loss or impending graft loss (eGFR $<30 \mathrm{ml} / \mathrm{min}$ and $\Delta \mathrm{eGFR}>30 \%$ ) was also significantly greater in the high-risk group $(\mathrm{p}<0.001$, Fig. $7 \mathrm{G}-\mathrm{H})$. In a multivariate Cox proportional hazard model, an increase in the T1B IL-10/TNF $\alpha$ ratio was associated with a significantly lower hazard 
of death-censored graft loss $(\mathrm{p}=0.004)$, overall graft loss $(\mathrm{p}=0.001)$, or the composite endpoint ( $<<0.001)$, independent of factors commonly associated with poor transplant outcomes such as eGFR at 3 months, DGF, and DSA (table S4). Finally, in the subset of patients with no rejection at 3 months, biomarker high-risk patients still had significantly worse 5-year overall and deathcensored graft survival ( $\mathrm{p}=0.001$ or lower) and a higher incidence of the composite endpoint as compared to low-risk patients ( $\mathrm{p}=0.002$ or lower), highlighting the ability of the biomarker to risk-stratify apparently stable renal transplant patients who lacked concomitant or prior rejection at 3 months (fig. S13). Thus, a low T1B IL-10/TNF $\alpha$ ratio strongly predicted TCMR and was also associated with early allograft scarring, progressive decline in allograft function, and graft loss.

Effect of TNF-blockade on B cells: Since B cells in high-risk patients exhibited a more proinflammatory cytokine profile based on their low IL-10/TNF $\alpha$ ratio, we compared the regulatory activity of B cells in PBMCs from high- and low-risk patients by examining the effect of B cell depletion on cytokine expression by activated $\mathrm{CD}^{+} \mathrm{T}$ cells (fig. S14A). B cell depletion significantly increased $\mathrm{TNF} \alpha(\mathrm{p}=0.02)$ and $\operatorname{IFN} \gamma(\mathrm{p}=0.02)$ expression and decreased IL-10 expression $(\mathrm{p}=0.02)$ by $\mathrm{CD} 4^{+} \mathrm{T}$ cells in $\mathrm{PBMCs}$ from low-risk patients, suggesting that $\mathrm{B}$ cells were exerting regulatory activity (Fig. 8A, fig. S14B). In contrast, B cell depletion increased expression of the regulatory cytokine IL-10 by $\mathrm{CD}^{+}{ }^{+} \mathrm{T}$ cells in PBMCs from high-risk patients, suggesting that B cells in these patients were predominantly pro-inflammatory. Next, B cells from healthy volunteers were stimulated in the presence or absence of anti-TNF $\alpha$ (fig. S15A). Anti-TNF $\alpha$ treatment not only increased the IL-10/TNF $\alpha$ ratio in B cells and individual B cell subsets but also inhibited the expression of other pro-inflammatory cytokines including IL-6, IL12, and Granulocyte-macrophage colony-stimulating factor (GM-CSF, Fig. 8B, fig. S15B, fig. 
S16). B cells were then washed and cultured with activated autologous $\mathrm{CD} 4^{+} \mathrm{T}$ cells to examine B cell regulatory activity in an established in vitro assay (fig. S17A)(22, 24). Compared to untreated B cells, those treated with anti-TNF $\alpha$ significantly increased IL-10 (p=0.003) and decreased $\mathrm{TNF} \alpha(\mathrm{p}=0.003)$ expression by $\mathrm{CD}^{+} \mathrm{T}$ cells (Fig. 8C, fig. S17B). Finally, we examined the effect of anti-TNF $\alpha$ on differentiation of B cells into plasmablasts in vitro. TNF blockade significantly reduced plasmablast differentiation $(\mathrm{p}<0.001)$, and the resulting plasmablasts expressed increased IL-10 (p<0.001, Fig. 8D and E, fig. S18). TNF blockade also strongly reduced secretion of the complement-fixing IgG1 and IgG3 by the plasmablasts (Fig. 8F). Thus, TNF-blockade in vitro restored B cell regulatory activity, reduced differentiation of B cells into plasmablasts, skewed them towards IL-10-expressing regulatory cells, and inhibited the secretion of complement-fixing antibodies.

\section{Discussion:}

Chronic allograft failure is a leading cause of renal allograft loss. Previous studies have shown that TCMR in the first year, particularly within the first six months, has a detrimental effect on long-term graft survival(25). Here, inclusion of surveillance biopsies to detect scTCMR at both early and late time points within the first year revealed that early TCMR that resolved with treatment actually had a relatively small impact on graft survival. In contrast, patients with early TCMR that was recurrent or recalcitrant and patients with late TCMR were at higher risk for graft loss. Most late TCMR is clinically silent and is already associated with increased allograft scarring. Thus, it is imperative to find predictive biomarkers that can identify these high-risk patients early enough so that pre-emptive therapy can be instituted.

In this study, we prospectively tested and validated the T1B IL-10/TNF $\alpha$ ratio as a strong predictor of clinical and subclinical TCMR in the first year. At 3 months, this biomarker 
identified high-risk patients, $60 \%$ of whom had early TCMR, which recurred in $50 \%$ despite anti-rejection therapy. Moreover, amongst the $40 \%$ without early TCMR, $74 \%$ had de novo late TCMR. In marked contrast, $<10 \%$ of low-risk patients had either early or late rejection. Standard of care immunosuppression is failing this high immunological risk cohort, who subsequently exhibit decreased GFR and poorer graft survival whether or not they had early TCMR. Thus, this biomarker will allow introduction of truly pre-emptive therapy by identifying high-risk patients with an average lead time of about 8 months. Since the majority of all TCMR in the first year is subclinical and overwhelmingly occurs in high-risk patients, the T1B IL-10/TNF $\alpha$ ratio may also inform the use of surveillance biopsies in renal transplantation.

The clinical utility of any biomarker relies on generalizability. The T1B IL-10/TNF $\alpha$ ratio strongly predicts TCMR irrespective of donor type, HLA matching, DGF, DSA, induction immunosuppression, CNI adherence, and whether or not surveillance biopsies were performed. Further, the biomarker was not affected by opportunistic viral infection. However, there are several limitations. Although the T1B IL-10/TNF $\alpha$ ratio could predict both scTCMR and cTCMR with similar sensitivity and specificity, the ratio did not differ in patients according to grade of TCMR. Thus, the biomarker cannot be used to risk-stratify patients according to the severity of rejection. Regardless, the biomarker did prognosticate renal transplant outcomes. Importantly, the biomarker identifies patients at high risk for poor outcomes despite treatment of their rejection episodes. However, the study was not designed to examine the effect of antirejection therapy on the biomarker. The observed rate of ABMR in this non-selected group of consecutive renal transplant recipients was 3\% - similar to that reported in other studies of nonsensitized renal transplant recipients on tacrolimus-based immunosuppression in the first posttransplant year(26-29). This low incidence of ABMR precluded our ability to determine whether 
the biomarker could differentiate between TCMR and ABMR. Finally, although the biomarker is based on a cellular assay, the inter-personal and intra-personal CV were low (12\% and 4\%, respectively). The generalizability and low variability of the biomarker should allow for widespread application (30).

B cells produce antibodies that can contribute to allograft rejection $(8,31)$. However, B cells can also either augment or inhibit effector $\mathrm{T}$ cell responses in various disease settings, highlighting their role as both proinflammatory effector B cells (Beff) and Bregs (32-36). In clinical transplantation, depletion of B cells in the peri-transplant period with Rituximab (humanized anti-CD20), markedly increased acute renal allograft rejection and worsened cardiac allograft vasculopathy, suggesting that Bregs play an important role in engraftment $(37,38)$. However, there exists no specific marker to identify Bregs, and they are most commonly identified by their expression of IL-10. In mice, specific deletion of B cell-expressed IL-10 markedly increases the inflammatory response in vivo, and addition of anti-IL-10 blocks in vitro human Breg activity (22, 39). Various human B cell phenotypic subsets are reportedly enriched for IL-10 expression, including canonical $\mathrm{B}$ cell subsets, $\mathrm{CD} 138^{+}$plasmablasts, $\mathrm{CD} 24^{\mathrm{hi}} \mathrm{CD} 27^{+}$memory, $\mathrm{CD}_{25}{ }^{\text {hi CD} 71}{ }^{\text {hi CD73- }}{ }^{-}$TNFR2 ${ }^{+}, \mathrm{TIM}^{+}$, and $\mathrm{CD} 271^{+} \mathrm{CD} 431^{+} \mathrm{CD} 11 \mathrm{~b}^{+}$B cells; however, only a small proportion of B cells within each of these subpopulations actually expresses IL-10, and each comprises only a fraction of all $\mathrm{IL}-10^{+} \mathrm{B}$ cells $(17,40-47)$. While all canonical B cell subsets express IL-10, TrB cells are the most enriched.(22, 24). Canonical B cell subsets also express pro-inflammatory cytokines like $\mathrm{TNF} \alpha$, demonstrating that individual $\mathrm{B}$ cell subsets contain both Bregs and Beff. We have shown that "Breg activity" is best characterized by the ratio of IL-10/TNF $\alpha$ because this provides a read-out of the number of Bregs relative to proinflammatory Beff cells in any given subset, and this correlates with their in vitro suppressor 
activity. Thus, $\operatorname{TrB}$ cells have the highest IL-10/TNF $\alpha$ ratio and suppress autologous $\mathrm{T}$ cell proinflammatory cytokine expression in vitro. While anti-IL-10 diminished the in vitro Breg activity of $\operatorname{TrB}$ cells, anti-TNF $\alpha$ revealed the activity of Bregs within the naïve and memory B subsets. Thus, it is likely that all IL- $10^{+}$B cells are regulatory, but that the balance of IL-10/TNF $\alpha$ expression within a given subset best identifies the balance between Breg and Beff cells (22). Why the regulatory B cell balance (IL-10/TNF $\alpha$ ratio) within the T1B subset turns out to be the best predictive biomarker for renal allograft rejection and outcomes is not clear. TrB cells are short-lived immature B cells that either mature into naive B cells or undergo apoptosis. However, it is possible that $\operatorname{TrB}$ cells maintain their original cytokine profile when they mature or are activated in immune or parenchymal tissues (46).

The TIB cytokine ratio is distinct from other biomarkers in transplantation in that it identifies an immunological imbalance that might be amenable to therapeutic manipulation. Supporting this, we demonstrated that TNF-neutralization augments the T1B IL-10/TNF $\alpha$ ratio and these B cells exhibit increased in vitro Breg activity. Anti-TNF $\alpha$ also inhibited plasma cell differentiation and suppressed complement-fixing antibody secretion. Moreover, it has been shown that treatment of rheumatoid arthritis patients with anti-TNF $\alpha$ increases IL- $10^{+} \mathrm{B}$ cells in vivo, supporting the notion that TNF-blockade may work through modulation of Breg to Beff ratios(48). Although data in transplantation are limited, anti-TNF $\alpha$ successfully rescued a series of 9 small bowel allograft recipients who had rejection resistant to both steroids and $\mathrm{T}$ cell depletion therapy with OKT3 antibody(49). Thus, we provide a rationale for the use of anti-TNF $\alpha$ to improve clinical outcomes in immunologically high-risk renal transplant recipients by restoring Breg activity.

In conclusion, we identified an early immunological biomarker in renal transplant recipients that predicts subsequent TCMR and graft loss. By identifying high-risk patients before further 
damage and maturation of the immune response has occurred, this biomarker could be used to guide surveillance biopsies and personalize immunosuppression in attempts to alter clinical course. The evidence that TNF-blockade may reverse a Breg to Beff imbalance provides a rationale for testing this therapeutic approach in high-risk kidney transplant patients.

\section{Methods:}

\section{Study Design:}

This is a prospective observational study of non-preselected adult renal transplant recipients who underwent transplantation between January 2013 and December 2014 at University of Pittsburgh Medical Center (UPMC) to examine the role of B cells and their cytokines as predictive biomarkers for allograft rejection and subsequent outcomes. The biomarker was validated in a further prospective cohort of patients transplanted in 2015 from UPMC and in an independent cohort of patients transplanted between 2011 and 2014 at the Royal Free Hospital in London.

Outcomes Study: In a prospective observational study, we initially examined allograft outcomes in all adult kidney transplant recipients at the University of Pittsburgh Medical Center (UPMC) between 2013-2015 (n=596; Fig. 1A). Unless medically contraindicated, patients underwent two surveillance biopsies at 3 and 12 months in addition to for-cause biopsies. Surveillance biopsies were not performed if patients had a for-cause biopsy within 1 month. Based on the timing, biopsies were classified as either early (0-4 months) or late (5-12 months). Of the 596 total patients, $468(79 \%)$ had at least one biopsy in the first post-transplant year. 138 of these had one biopsy (early or late), while 330 had paired early and late biopsies (71\%). 128 (21\%) patients did not undergo any biopsies.

Biomarker study: All patients transplanted at UPMC between 2013 and 2015 were approached to participate in a biorepository where PBMCs were cryopreserved at regular intervals and at the 
time of any biopsies. Of the 468 who had at least one biopsy, 244 (52\%) consented to enroll in the biorepository and were utilized in the biomarker portion of this study (Fig. 2). Patients transplanted in 2013 and 2014 constituted the Training Set $(n=162)$. Four patients were excluded because they received prior Rituximab or had no viable cells. Patients transplanted in 2015 comprised the Internal Validation Set ( $\mathrm{n}=82) .327$ biopsies were performed in the Training Set (for-cause, 84; surveillance, 243), and 168 in the Internal Validation Set (for-cause, 55; surveillance, 113). In the training set, 121 (77\%) patients had paired early and late biopsies. In the Internal Validation Set, 53(64\%) had paired early and late biopsies. Patients were followed until March 2020.

A total of 95 patients transplanted between May 2011 and October 2014 at the Royal Free Hospital, London, constituted the External Validation Set. All patients were followed for 5 years to assess graft outcomes, and only underwent for-cause biopsies.

The study protocol was approved by the University of Pittsburgh IRB (\#PRO13060220, REN13040245/PRO12030552, PRO14040614) and the UK National Research Ethics Committee (\#10/H0711/36).

Immunosuppression: Induction immunosuppression consisted of either Thymoglobulin (6 $\mathrm{mg} / \mathrm{kg}$ total; UPMC) or Basiliximab (London) plus methylprednisolone $(500 \mathrm{mg})$. All patients underwent rapid 7-day prednisolone taper and were then maintained on Mycophenolate Mofetil (MMF) and Tacrolimus (TAC; target trough concentrations: $8-12 \mathrm{ng} / \mathrm{ml}$ for 3 months and 610ng/ml after 3 months). Patients with calculated panel reactive antibodies (cPRA) > 90\% were also maintained on oral prednisolone (5mg/day). Banff 1A or 1B TCMR, whether clinical or subclinical, was treated with three doses of methylprednisolone (250 mg each). Banff $\geq 2 \mathrm{~A}$ and steroid resistant TCMR were treated with Thymoglobulin (maximum $6 \mathrm{mg} / \mathrm{kg}$ ) over 4-5 days. 
Acute ABMR was treated with 4-6 treatments of plasmapheresis plus intravenous Immunoglobulin. Maintenance prednisolone (5mg/day) was added for all patients with rejection.

Monitoring: Blood was drawn at 0, 1, 3, 6, 9 and 12 months to monitor for DSA as well as BKV and CMV infections. DSA was assessed by One Lambda single antigen beads per manufacturer's instructions. An adjusted MFI of $\geq 1000$ was used to detect DSA. CMV and BK were assessed by the hospital clinical laboratory based on nucleic acid detection.

B cell cytokines and function: PBMCs were separated from peripheral blood by Ficoll density centrifugation and cryopreserved at each center. For analysis, PBMC aliquots were thawed and assessed by flow cytometry. In the Training Set, various B cell subsets and their IL-10/TNF $\alpha$ ratio were examined longitudinally in 430 PBMC samples analyzed 1, 3, 6, and 12 months posttransplant. Based on this, the T1B IL-10/TNF $\alpha$ ratio was examined at 3 months in the Validation Sets.

Monoclonal antibodies (mAbs) and biologic reagents: Anti-human fluorochrome-conjugated mAbs included: BUV-737-CD19, PE-Cy7-CD3, BV421-CD38, BV605-CD24, BUV395-CD27, AF488-IgD, APC-IgM, PECy7-CD138, PE-interleukin (IL)-10, PE-Texas Red-interferon gamma (IFN $\gamma$ ), and AF488-tumor necrosis factor alpha (TNF $\alpha$ ) from BD Biosciences. Functional grade anti-CD3 (HIT3a) was from BD Biosciences, chimeric anti-human TNFa (Infliximab) was from Janssen Pharmaceuticals. Resiquimod (R848) and recombinant human IL-2 (rhIL-2) were from R\&D systems and CpG-ODN-2006 was from Invivogen.

Assessment of the IL-10/TNFa ratio: PBMCs were suspended in RPMI-1640 supplemented with $10 \%$ fetal bovine serum (FBS), $1 \%$ penicillin-streptomycin, and L-glutamine at $2.5 \times 10^{6}$ cells/ml (complete RPMI) and stimulated for 24 hours on a monolayer of NIH 3T3cells stably 


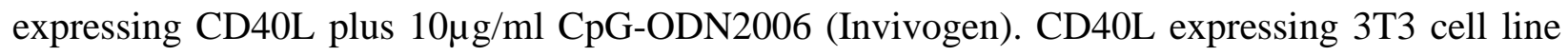
was kindly provided by Gordon Freeman from Dana-Farber Cancer Institute(51). Phorbol 12myristate 13-acetate (PMA, $50 \mathrm{ng} / \mathrm{ml}$ ), ionomycin (500ng/ml), and Brefeldin A were added for the last 5 hours of culture. Cells were stained with surface markers, fixed and permeabilized using the Cytofix/Cytoperm kit (BD Biosciences), then stained for intracellular cytokines (IL-10 and $\mathrm{TNF} \alpha$ ). Flow cytometry was performed using a BD LSR-Fortessa flow cytometer (Beckton Dickinson) and data analyzed using Kaluza software (Beckman Coulter). Cursors were set using isotype and fluorochrome-matched negative controls for intracellular staining. Total B cells were defined by surface expression as $\mathrm{CD}_{19}{ }^{+} \mathrm{CD}^{-}$, and $\mathrm{B}$ cell subsets further identified as: $\mathrm{CD} 24^{+++} \mathrm{CD} 38^{+++}$T1-Transitional B cells (T1B), CD24 ${ }^{++} \mathrm{CD} 38^{++}$T2-transitional B cells (T2B), $\mathrm{CD} 24^{+} \mathrm{CD} 38^{+}$naïve cells, and $\mathrm{CD} 24^{+++} \mathrm{CD} 38^{-}$memory cells. The gating strategies for individual T1 and T2 B cell subsets, IL-10 and TNF $\alpha$ expression, and the IL-10/TNF $\alpha$ ratio by these subsets is shown in fig. S19 and fig. S20 and has been described in previous studies $(22,23,52)$. The T1 and $\mathrm{T} 2$ subsets were readily distinguishable because the more immature T1 subset repopulates before the T2 subset after Thymoglobulin induction. Once established, the same gates were used in both validation cohorts.

$\underline{\text { B cell depletion and T cell cytokines: }} \mathrm{CD} 19^{+} \mathrm{B}$ cells were depleted from PBMCs of high-risk $(n=4)$ and low-risk $(n=4)$ patients from the UPMC cohort 3 months post-transplantation using immunomagnetic beads (Stem Cell Technologies) per manufacturer's instructions. Non-depleted PBMCs or those depleted of $\mathrm{CD} 19^{+} \mathrm{B}$ cells were cultured in 96 well u-bottom tissue culture plates (Corning), coated with purified anti-human CD3 mAb $(0.5 \mathrm{mg} / \mathrm{ml})$ for 72 hours. PMA, ionomycin, and Brefeldin A were added for the last 6 hours of the culture. After surface staining for $\mathrm{CD}^{+} \mathrm{T}$ cells and fixation, cells were permeabilized using the Cytofix/Cytoperm kit (BD 
Biosciences) and then stained for intracellular cytokines (IL-10, TNF $\alpha$ and IFN $\gamma$ ). $\mathrm{CD}^{+}{ }^{+} \mathrm{T}$ cell cytokines with or without B cell depletion were analyzed using a BD LSR-Fortessa.

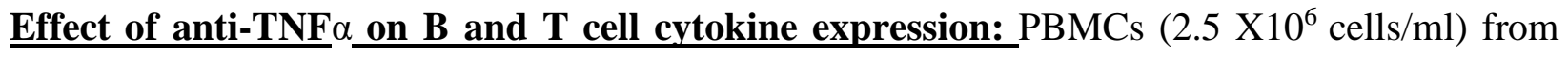
healthy volunteers $(n=8)$ were stimulated for 24 hours on a monolayer of NIH 3T3 cells stably expressing CD40L plus $10 \mu \mathrm{g} / \mathrm{ml} \mathrm{CpG-ODN2006} \mathrm{(Invivogen)} \mathrm{in} \mathrm{the} \mathrm{presence} \mathrm{of} \mathrm{anti-TNF} \alpha \mathrm{mAb}$ (infliximab $125 \mathrm{mg} / \mathrm{ml})$ or an isotype control (IgG1k). PMA (50 ng/ml), ionomycin (500ng/ml), and Brefeldin A were added for the last 5 hours of culture. IL-10 and TNF $\alpha$ expression in B cells and subsets were analyzed as detailed in the assessment of the IL-10/TNF $\alpha$ ratio section.

To assess the effect of anti-TNF $\alpha$ on B cell regulatory function, magnetically enriched B cells from 4 healthy volunteers were stimulated with anti-human CD40 mAb and CpG-ODN 2006 $(10 \mathrm{mg} / \mathrm{ml})$ for 24 hours in the presence or absence of anti-TNF $\alpha(125 \mathrm{mg} / \mathrm{ml})$. After 24 hours, both anti-TNF $\alpha$ treated and untreated B cells were washed three times in complete RPMI. Washed B cells were then co-cultured 1:1 with magnetically purified CD4 ${ }^{+} \mathrm{T}$ cells in 96 well ubottom tissue culture plates (Corning) coated with purified anti-human CD3 mAb $(0.5 \mathrm{mg} / \mathrm{ml})$ for 72 hours. $\mathrm{CD}^{+} \mathrm{T}$ cell-expressed IL-10 and TNF $\alpha$ were analyzed by intracellular staining as described in the $\mathrm{B}$ cell depletion and $\mathrm{T}$ cell cytokines section.

Plasmablast differentiation: PBMCs $\left(1 \times 10^{6} / \mathrm{ml}\right)$ from 17 UPMC renal allograft recipients three months post-transplantation were suspended in complete RPMI at $2.5 \times 10^{6}$ cells $/ \mathrm{ml}$ and stimulated for 6 days with rhIL-2 (1000 units/ml) and Resiquimod $(2.5 \mathrm{mg} / \mathrm{ml})(53,54)$. On day 6 , an aliquot of cell culture supernatant was removed and cryopreserved for analysis of $\operatorname{IgG}$ subclasses by ELISA per manufacturer's instructions (Invitrogen). Following this, PMA (50 $\mathrm{ng} / \mathrm{ml})$, ionomycin $(500 \mathrm{ng} / \mathrm{ml})$, and Brefeldin A were added to the cell culture for 5 hours. The 
phenotype of the cultured cells was then assessed using anti-human mAbs for CD19, IgD, CD24, CD27 and CD38 followed by intracellular cytokine staining for IL-10.

Outcomes: Outcomes were biopsy-proven rejection in the first post-transplant year, interstitial fibrosis and tubular atrophy (IFTA) at 1 year, eGFR at 1-4 years, graft loss at 5 years, and a composite end-point of graft loss or impending graft loss (eGFR $<30 \mathrm{ml} / \mathrm{min}$ and reduction in eGFR $>30 \%$ from baseline) at 5 years. Biopsies were scored by transplant pathologists using Banff 2013 criteria to define T cell-mediated rejection (TCMR) or antibody-mediated rejection (ABMR)(50). Herein, the term TCMR refers to Banff grade 1A rejection or greater. Diagnosis of clinical TCMR (cTCMR) was based on clinically indicated (for-cause) biopsies and subclinical TCMR (scTCMR), on surveillance biopsies (performed without evidence of renal dysfunction). cTCMR rate was based on the total number of patients in the cohort, whereas scTCMR rate was based on the number of patients who underwent surveillance biopsies. eGFR was estimated by chronic kidney disease epidemiology collaboration(CKD EPI) equation.

Statistical analysis: Continuous variables were presented as mean \pm SEM and categorical variables as percentages. Continuous variables were compared using Mann-Whitney U test. Multiple group comparison used ANOVA with Dunnet post-hoc correction or Kruskal Wallis test. Chi-squared test compared categorical variables. Non-parametric paired comparisons used Wilcoxon matched pairs signed rank test. Predicted probabilities and odds ratios for acute rejection were calculated using an unadjusted logistic regression. ROC curve analysis was used to obtain optimal sensitivity and specificity of the studied markers. Given the asymmetric nature of the outcome (TCMR), Precision-Recall Curves (PRCs) were utilized to assess the positive predictive value of the T1B IL-10/TNF $\alpha$ ratio at the given sensitivity. 
Further, patients from the Training Set and the two validation sets were combined and stratified by key clinical variables including, age (classified as younger or older based on age greater or less than the median); gender (male or female); ethnicity (Caucasian or others); donor source (live vs. deceased (including both brain dead and circulatory dead donors)); HLA mismatches (classified as higher or lower based on values greater or less than the median); induction immunosuppression (Thymoglobulin or Basiliximab); DGF (DGF or primary graft function); DSA in the first post-transplant year (detected or not detected); serum creatinine at 3 mos (classified as higher or lower based on values greater or less than the median); CMV (more than 5000 copies/ml) or BK viremia (more than 10000 copies /ml) by PCR; and calcineurin inhibitor (CNI) adherence assessed by the measurement of CNI intra-patient variability (IPV), as previously described(55-57). A CNI-IPV cut-off value of $>35 \%$ was used to define nonadherence, as described previously(27). Odds ratio (OR) and predicted probability for TCMR was calculated using T1B IL-10/TNF $\alpha$ ratio at 3 months as a continuous variable by logistic regression and ROC curve analysis performed for each of the above-mentioned strata.

Renal function assessed by eGFR was compared longitudinally between the high- and the lowrisk patients using repeated measures ANOVA (analysis of variance) with Geisser Greenhouse correction. eGFR values at different time points were compared between the groups by Sidak post-hoc test. Random missing values of eGFR were addressed by multiple imputation (5 imputations). Overall graft loss, death censored graft loss and a composite endpoint of graft loss and impending graft loss were analyzed by the Kaplan-Meier method and survival curves were compared between high- and low-risk patients by Log-Rank test. Impending graft loss was defined as eGFR of $<30 \mathrm{ml} / \mathrm{min}$ and a $>30 \%$ decline in eGFR from the baseline at 3 months(27). In a multivariable Cox proportional hazards model, the hazard for graft loss with each unit 
increase in the biomarker value was analyzed independent of eGFR, DSA and DGF (factors commonly associated with poor graft outcomes). 


\section{Supplementary Materials:}

Fig. S1. TCMR and five-year death censored graft survival (GS).

Fig. S2. Longitudinal analysis of proportion of total B cells, B cell subsets, and their Interleukin (IL)-10/tumor necrosis factor alpha (TNF $\alpha)$ ratios over time.

Fig. S3. IL-10/TNF $\alpha$ ratio in indicated B cell subsets at 3 months in patients with and without evidence of TCMR.

Fig. S4. T1B IL-10/TNF $\alpha$ ratio according to TCMR type or grade.

Fig. S5. Rate of TCMR at various T1B IL-10/TNF $\alpha$ ratio cut-offs in the Training Set.

Fig. S6. Precision Recall Curves for Training and Internal Validation Sets.

Fig. S7. Concurrent or later T Cell Mediated Rejection (TCMR) and T1B IL-10/TNF $\alpha$ ratio in Training and Validation Sets.

Fig. S8. T1B IL-10/TNF $\alpha$ ratio and TCMR in the External Validation Set.

Fig. S9. T1B IL-10/TNF $\alpha$ ratio in patients with and without donor-specific antibodies (DSA).

Fig. S10. T1B IL-10/TNFa ratio in patients with and without opportunistic viral infections (CMV or BKV).

Fig. S11. Coefficient of Variation (CV) for the determination of B cell subsets and T1B IL$10 / \mathrm{TNF} \alpha$ ratio.

Fig. S12. T1B IL-10/TNF $\alpha$ ratio and IFTA at 1 year.

Fig. S13. Association between T1B IL-10/TNF $\alpha$ ratio and long-term clinical outcomes in patients without early TCMR. 
Fig. S14. The effect of B cell depletion on $\mathrm{CD}^{+} \mathrm{T}$ cell cytokines in high- and low-risk patients.

Fig. S15. Effect of anti-TNF on B cell subset IL-10/TNFa ratios.

Fig. S16. Effect of anti-TNF $\alpha$ on B cell subset IL-6, GM-CSF and IL-12 expression.

Fig. S17. Effect of anti-TNF $\alpha$ on B cell regulatory activity.

Fig. S18. Effect of anti-TNF $\alpha$ treatment on B cell differentiation into plasmablasts ex vivo.

Fig. S19. Gating strategy for T1B cells.

Fig. S20. IL-10/TNFa ratio in B cells and B cell subsets.

Table S1. Baseline characteristics of the study cohort versus patients who did not participate.

Table S2. Logistic regression, B cell parameters, and TCMR .

Table S3. Baseline characteristics of the External Validation Set.

Table S4. Multivariable analysis of T1B IL-10/TNF $\alpha$ ratio and graft outcomes.

Data File S1. Raw data for main figures and supplementary figures. 


\section{References:}

1. K. E. Lamb, S. Lodhi, H. U. Meier-Kriesche, Long-term renal allograft survival in the United States: a critical reappraisal. Am J Transplant 11, 450-462 (2011); published online EpubMar (10.1111/j.1600-6143.2010.03283.x).

2. S. Shishido, H. Asanuma, H. Nakai, Y. Mori, H. Satoh, I. Kamimaki, H. Hataya, M. Ikeda, M. Honda, A. Hasegawa, The impact of repeated subclinical acute rejection on the progression of chronic allograft nephropathy. J Am Soc Nephrol 14, 1046-1052 (2003); published online EpubApr (10.1097/01.asn.0000056189.02819.32).

3. S. Gourishankar, R. Leduc, J. Connett, J. M. Cecka, F. Cosio, A. Fieberg, R. Gaston, P. Halloran, L. Hunsicker, B. Kasiske, D. Rush, J. Grande, R. Mannon, A. Matas, Pathological and clinical characterization of the 'troubled transplant': data from the DeKAF study. Am J Transplant 10, 324-330 (2010); published online EpubFeb (10.1111/j.1600-6143.2009.02954.x).

4. J. Kurtkoti, V. Sakhuja, K. Sud, M. Minz, R. Nada, H. S. Kohli, K. L. Gupta, K. Joshi, V. Jha, The utility of 1- and 3-month protocol biopsies on renal allograft function: a randomized controlled study. Am J Transplant 8, 317-323 (2008); published online EpubFeb (10.1111/j.1600-6143.2007.02049.x).

5. A. Loupy, D. Vernerey, C. Tinel, O. Aubert, J. P. Duong van Huyen, M. Rabant, J. Verine, D. Nochy, J. P. Empana, F. Martinez, D. Glotz, X. Jouven, C. Legendre, C. Lefaucheur, Subclinical rejection phenotypes at 1 year post-transplant and outcome of kidney allografts. J Am Soc Nephrol 26, 1721-1731 (2015); published online EpubJul (10.1681/ASN.2014040399).

6. D. N. Rush, P. Nickerson, J. R. Jeffery, R. M. McKenna, P. C. Grimm, J. Gough, Protocol biopsies in renal transplantation: research tool or clinically useful? Curr Opin Nephrol Hypertens 7, 691-694 (1998); published online EpubNov (10.1097/00041552199811000-00012).

7. B. Kaplan, J. Schold, H. U. Meier-Kriesche, Poor predictive value of serum creatinine for renal allograft loss. Am J Transplant 3, 1560-1565 (2003); published online EpubDec (10.1046/j.1600-6135.2003.00275.x).

8. A. Loupy, C. Lefaucheur, D. Vernerey, C. Prugger, J. P. Duong van Huyen, N. Mooney, C. Suberbielle, V. Fremeaux-Bacchi, A. Mejean, F. Desgrandchamps, D. Anglicheau, D. Nochy, D. Charron, J. P. Empana, M. Delahousse, C. Legendre, D. Glotz, G. S. Hill, A. Zeevi, X. Jouven, Complement-binding anti-HLA antibodies and kidney-allograft 
survival. N Engl J Med 369, 1215-1226 (2013); published online EpubSep 26 (10.1056/NEJMoa1302506).

9. M. Suthanthiran, J. E. Schwartz, R. Ding, M. Abecassis, D. Dadhania, B. Samstein, S. J. Knechtle, J. Friedewald, Y. T. Becker, V. K. Sharma, N. M. Williams, C. S. Chang, C. Hoang, T. Muthukumar, P. August, K. S. Keslar, R. L. Fairchild, D. E. Hricik, P. S. Heeger, L. Han, J. Liu, M. Riggs, D. N. Ikle, N. D. Bridges, A. Shaked, I. Clinical Trials in Organ Transplantation 04 Study, Urinary-cell mRNA profile and acute cellular rejection in kidney allografts. $N$ Engl J Med 369, 20-31 (2013); published online EpubJul 4 (10.1056/NEJMoa1215555).

10. S. Roedder, T. Sigdel, N. Salomonis, S. Hsieh, H. Dai, O. Bestard, D. Metes, A. Zeevi, A. Gritsch, J. Cheeseman, C. Macedo, R. Peddy, M. Medeiros, F. Vincenti, N. Asher, O. Salvatierra, R. Shapiro, A. Kirk, E. F. Reed, M. M. Sarwal, The kSORT assay to detect renal transplant patients at high risk for acute rejection: results of the multicenter AART study. PLoS Med 11, e1001759 (2014); published online EpubNov (10.1371/journal.pmed.1001759).

11. D. E. Hricik, P. Nickerson, R. N. Formica, E. D. Poggio, D. Rush, K. A. Newell, J. Goebel, I. W. Gibson, R. L. Fairchild, M. Riggs, K. Spain, D. Ikle, N. D. Bridges, P. S. Heeger, C.-. consortium, Multicenter validation of urinary CXCL9 as a risk-stratifying biomarker for kidney transplant injury. Am J Transplant 13, 2634-2644 (2013); published online EpubOct (10.1111/ajt.12426).

12. J. J. Friedewald, S. M. Kurian, R. L. Heilman, T. C. Whisenant, E. D. Poggio, C. Marsh, P. Baliga, J. Odim, M. M. Brown, D. N. Ikle, B. D. Armstrong, J. I. Charette, S. S. Brietigam, N. Sustento-Reodica, L. Zhao, M. Kandpal, D. R. Salomon, M. M. Abecassis, T. Clinical Trials in Organ, Development and clinical validity of a novel blood-based molecular biomarker for subclinical acute rejection following kidney transplant. Am J Transplant 19, 98-109 (2019); published online EpubJan (10.1111/ajt.15011).

13. W. Zhang, Z. Yi, K. L. Keung, H. Shang, C. Wei, P. Cravedi, Z. Sun, C. Xi, C. Woytovich, S. Farouk, W. Huang, K. Banu, L. Gallon, C. N. Magee, N. Najafian, M. Samaniego, A. Djamali, S. I. Alexander, I. A. Rosales, R. N. Smith, J. Xiang, E. Lerut, D. Kuypers, M. Naesens, P. J. O'Connell, R. Colvin, M. C. Menon, B. Murphy, A Peripheral Blood Gene Expression Signature to Diagnose Subclinical Acute Rejection. J Am Soc Nephrol 30, 1481-1494 (2019); published online EpubAug (10.1681/ASN.2018111098).

14. W. Zhang, Z. Yi, C. Wei, K. L. Keung, Z. Sun, C. Xi, C. Woytovich, S. Farouk, L. Gallon, M. C. Menon, C. Magee, N. Najafian, M. D. Samaniego, A. Djamali, S. I. Alexander, I. A. Rosales, R. N. Smith, P. J. O'Connell, R. Colvin, P. Cravedi, B. Murphy, 
Pretransplant transcriptomic signature in peripheral blood predicts early acute rejection. JCI Insight 4, (2019); published online EpubJun 6 (10.1172/jci.insight.127543).

15. J. Y. C. Yang, R. D. Sarwal, T. K. Sigdel, I. Damm, B. Rosenbaum, J. M. Liberto, C. Chan-On, J. M. Arreola-Guerra, J. Alberu, F. Vincenti, M. M. Sarwal, A urine score for noninvasive accurate diagnosis and prediction of kidney transplant rejection. Sci Transl Med 12, (2020); published online EpubMar 18 (10.1126/scitranslmed.aba2501).

16. S. Fillatreau, C. H. Sweenie, M. J. McGeachy, D. Gray, S. M. Anderton, B cells regulate autoimmunity by provision of IL-10. Nat Immunol 3, 944-950 (2002); published online EpubOct (10.1038/ni833).

17. K. Mohib, A. Cherukuri, D. M. Rothstein, Regulatory B cells and transplantation: almost prime time? Curr Opin Organ Transplant 23, 524-532 (2018); published online EpubOct (10.1097/MOT.0000000000000559).

18. C. Mauri, A. Bosma, Immune regulatory function of B cells. Annu Rev Immunol 30, 221241 (2012)10.1146/annurev-immunol-020711-074934).

19. P. Neves, V. Lampropoulou, E. Calderon-Gomez, T. Roch, U. Stervbo, P. Shen, A. A. Kuhl, C. Loddenkemper, M. Haury, S. A. Nedospasov, S. H. Kaufmann, U. Steinhoff, D. P. Calado, S. Fillatreau, Signaling via the MyD88 adaptor protein in B cells suppresses protective immunity during Salmonella typhimurium infection. Immunity 33, 777-790 (2010); published online EpubNov 24 (10.1016/j.immuni.2010.10.016).

20. E. C. Rosser, C. Mauri, Regulatory B cells: origin, phenotype, and function. Immunity $\mathbf{4 2 \text { , }}$ 607-612 (2015); published online EpubApr 21 (10.1016/j.immuni.2015.04.005).

21. P. Shen, S. Fillatreau, Antibody-independent functions of B cells: a focus on cytokines. Nat Rev Immunol 15, 441-451 (2015); published online EpubJul (10.1038/nri3857).

22. A. Cherukuri, D. M. Rothstein, B. Clark, C. R. Carter, A. Davison, M. HernandezFuentes, E. Hewitt, A. D. Salama, R. J. Baker, Immunologic human renal allograft injury associates with an altered IL-10/TNF-alpha expression ratio in regulatory B cells. $J$ Am Soc Nephrol 25, 1575-1585 (2014); published online EpubJul (10.1681/ASN.2013080837).

23. A. Cherukuri, A. D. Salama, C. R. Carter, D. Landsittel, G. Arumugakani, B. Clark, D. M. Rothstein, R. J. Baker, Reduced human transitional B cell T1/T2 ratio is associated 
with subsequent deterioration in renal allograft function. Kidney Int 91, 183-195 (2017); published online EpubJan (10.1016/j.kint.2016.08.028).

24. P. A. Blair, L. Y. Norena, F. Flores-Borja, D. J. Rawlings, D. A. Isenberg, M. R. Ehrenstein, C. Mauri, CD19(+)CD24(hi)CD38(hi) B cells exhibit regulatory capacity in healthy individuals but are functionally impaired in systemic Lupus Erythematosus patients. Immunity 32, 129-140 (2010); published online EpubJan 29 (10.1016/j.immuni.2009.11.009).

25. P. A. Clayton, S. P. McDonald, G. R. Russ, S. J. Chadban, Long-Term Outcomes after Acute Rejection in Kidney Transplant Recipients: An ANZDATA Analysis. J Am Soc Nephrol 30, 1697-1707 (2019); published online EpubSep (10.1681/ASN.2018111101).

26. H. Ekberg, H. Tedesco-Silva, A. Demirbas, S. Vitko, B. Nashan, A. Gurkan, R. Margreiter, C. Hugo, J. M. Grinyo, U. Frei, Y. Vanrenterghem, P. Daloze, P. F. Halloran, E. L.-S. Study, Reduced exposure to calcineurin inhibitors in renal transplantation. $N$ Engl J Med 357, 2562-2575 (2007); published online EpubDec 20 (10.1056/NEJMoa067411).

27. A. Cherukuri, R. Mehta, A. Sharma, P. Sood, A. Zeevi, A. D. Tevar, D. M. Rothstein, S. Hariharan, Post-transplant donor specific antibody is associated with poor kidney transplant outcomes only when combined with both T-cell-mediated rejection and nonadherence. Kidney Int 96, 202-213 (2019); published online EpubJul (10.1016/j.kint.2019.01.033).

28. C. Puttarajappa, R. Shapiro, H. P. Tan, Antibody-mediated rejection in kidney transplantation: a review. J Transplant 2012, 193724 (2012)10.1155/2012/193724).

29. S. Davis, J. E. Cooper, Acute antibody-mediated rejection in kidney transplant recipients. Transplant Rev (Orlando) 31, 47-54 (2017); published online EpubJan (10.1016/j.trre.2016.10.004).

30. Z. C. Cui, Allowable limit of error in clinical chemistry quality control. Clin Chem 35, 630-631 (1989); published online EpubApr (10.1093/clinchem/35.4.630).

31. C. Wiebe, I. W. Gibson, T. D. Blydt-Hansen, M. Karpinski, J. Ho, L. J. Storsley, A. Goldberg, P. E. Birk, D. N. Rush, P. W. Nickerson, Evolution and clinical pathologic correlations of de novo donor-specific HLA antibody post kidney transplant. Am J Transplant 12, 1157-1167 (2012); published online EpubMay (10.1111/j.16006143.2012.04013.x). 
32. Q. Ding, M. Yeung, G. Camirand, Q. Zeng, H. Akiba, H. Yagita, G. Chalasani, M. H. Sayegh, N. Najafian, D. M. Rothstein, Regulatory B cells are identified by expression of TIM-1 and can be induced through TIM-1 ligation to promote tolerance in mice. The Journal of clinical investigation 121, 3645-3656 (2011); published online EpubSep (10.1172/JCI46274).

33. R. Li, A. Rezk, Y. Miyazaki, E. Hilgenberg, H. Touil, P. Shen, C. S. Moore, L. Michel, F. Althekair, S. Rajasekharan, J. L. Gommerman, A. Prat, S. Fillatreau, A. Bar-Or, B. c. i. M. S. T. Canadian, Proinflammatory GM-CSF-producing B cells in multiple sclerosis and B cell depletion therapy. Sci Transl Med 7, 310 ra166 (2015); published online EpubOct 21 (10.1126/scitranslmed.aab4176).

34. A. C. Lino, T. Dorner, A. Bar-Or, S. Fillatreau, Cytokine-producing B cells: a translational view on their roles in human and mouse autoimmune diseases. Immunol Rev 269, 130-144 (2016); published online EpubJan (10.1111/imr.12374).

35. Q. Ding, K. Mohib, V. K. Kuchroo, D. M. Rothstein, TIM-4 Identifies IFN-gammaExpressing Proinflammatory B Effector 1 Cells That Promote Tumor and Allograft Rejection. J Immunol 199, 2585-2595 (2017); published online EpubOct 1 (10.4049/jimmunol.1602107).

36. A. Cherukuri, K. Mohib, D.M. Rothstein., Regulatory B cells: TIM-1, Transplant Tolerance, and Rejection. Immunological reviews, (in press).

37. M. R. Clatworthy, C. J. Watson, G. Plotnek, V. Bardsley, A. N. Chaudhry, J. A. Bradley, K. G. Smith, B-cell-depleting induction therapy and acute cellular rejection. $N$ Engl J Med 360, 2683-2685 (2009); published online EpubJun 18 (10.1056/NEJMc0808481).

38. R. C. Starling, B. Armstrong, N. D. Bridges, H. Eisen, M. M. Givertz, A. G. Kfoury, J. Kobashigawa, D. Ikle, Y. Morrison, S. Pinney, J. Stehlik, S. Tripathi, M. H. Sayegh, A. Chandraker, C.-S. Investigators, Accelerated Allograft Vasculopathy With Rituximab After Cardiac Transplantation. J Am Coll Cardiol 74, 36-51 (2019); published online EpubJul 9 (10.1016/j.jacc.2019.04.056).

39. K. Mohib, A. Cherukuri, Y. Zhou, Q. Ding, S. C. Watkins, D. M. Rothstein, Antigendependent interactions between regulatory $\mathrm{B}$ cells and $\mathrm{T}$ cells at the T:B border inhibit subsequent T cell interactions with DCs. Am J Transplant 20, $52-63$ (2020); published online EpubJan (10.1111/ajt.15546).

40. W. van de Veen, B. Stanic, G. Yaman, M. Wawrzyniak, S. Sollner, D. G. Akdis, B. Ruckert, C. A. Akdis, M. Akdis, IgG4 production is confined to human IL-10-producing 
regulatory B cells that suppress antigen-specific immune responses. J Allergy Clin Immunol 131, 1204-1212 (2013); published online EpubApr (10.1016/j.jaci.2013.01.014).

41. O. Ticha, L. Moos, H. Wajant, I. Bekeredjian-Ding, Expression of Tumor Necrosis Factor Receptor 2 Characterizes TLR9-Driven Formation of Interleukin-10-Producing B Cells. Front Immunol 8, 1951 (2017)10.3389/fimmu.2017.01951).

42. O. Aravena, A. Ferrier, M. Menon, C. Mauri, J. C. Aguillon, L. Soto, D. Catalan, TIM-1 defines a human regulatory B cell population that is altered in frequency and function in systemic sclerosis patients. Arthritis Res Ther 19, 8 (2017); published online EpubJan 19 (10.1186/s13075-016-1213-9).

43. D. O. Griffin, T. L. Rothstein, Human "orchestrator" CD11b(+) B1 cells spontaneously secrete interleukin-10 and regulate T-cell activity. Mol Med 18, 1003-1008 (2012); published online EpubSep 7 (10.2119/molmed.2012.00203).

44. Y. Iwata, T. Matsushita, M. Horikawa, D. J. Dilillo, K. Yanaba, G. M. Venturi, P. M. Szabolcs, S. H. Bernstein, C. M. Magro, A. D. Williams, R. P. Hall, E. W. St Clair, T. F. Tedder, Characterization of a rare IL-10-competent B-cell subset in humans that parallels mouse regulatory B10 cells. Blood 117, 530-541 (2011); published online EpubJan 13 (10.1182/blood-2010-07-294249).

45. M. Chesneau, L. Michel, E. Dugast, A. Chenouard, D. Baron, A. Pallier, J. Durand, F. Braza, P. Guerif, D. A. Laplaud, J. P. Soulillou, M. Giral, N. Degauque, E. Chiffoleau, S. Brouard, Tolerant Kidney Transplant Patients Produce B Cells with Regulatory Properties. J Am Soc Nephrol 26, 2588-2598 (2015); published online EpubOct (10.1681/ASN.2014040404).

46. M. Matsumoto, A. Baba, T. Yokota, H. Nishikawa, Y. Ohkawa, H. Kayama, A. Kallies, S. L. Nutt, S. Sakaguchi, K. Takeda, T. Kurosaki, Y. Baba, Interleukin-10-producing plasmablasts exert regulatory function in autoimmune inflammation. Immunity 41, 10401051 (2014); published online EpubDec 18 (10.1016/j.immuni.2014.10.016).

47. A. Cherukuri, Q. Ding, A. Sharma, K. Mohib, D. M. Rothstein, Regulatory and Effector B Cells: A New Path Toward Biomarkers and Therapeutic Targets to Improve Transplant Outcomes? Clin Lab Med 39, 15-29 (2019); published online EpubMar (10.1016/j.cll.2018.10.011). 
48. Z. Banko, J. Pozsgay, T. Gati, B. Rojkovich, I. Ujfalussy, G. Sarmay, Regulatory B cells in rheumatoid arthritis: Alterations in patients receiving anti-TNF therapy. Clin Immunol 184, 63-69 (2017); published online EpubNov (10.1016/j.clim.2017.05.012).

49. U. A. Gerlach, M. Koch, H. P. Muller, W. Veltzke-Schlieker, P. Neuhaus, A. Pascher, Tumor necrosis factor alpha inhibitors as immunomodulatory antirejection agents after intestinal transplantation. Am J Transplant 11, 1041-1050 (2011); published online EpubMay (10.1111/j.1600-6143.2011.03497.x).

50. M. Haas, B. Sis, L. C. Racusen, K. Solez, D. Glotz, R. B. Colvin, M. C. Castro, D. S. David, E. David-Neto, S. M. Bagnasco, L. C. Cendales, L. D. Cornell, A. J. Demetris, C. B. Drachenberg, C. F. Farver, A. B. Farris, 3rd, I. W. Gibson, E. Kraus, H. Liapis, A. Loupy, V. Nickeleit, P. Randhawa, E. R. Rodriguez, D. Rush, R. N. Smith, C. D. Tan, W. D. Wallace, M. Mengel, c. Banff meeting report writing, Banff 2013 meeting report: inclusion of c4d-negative antibody-mediated rejection and antibody-associated arterial lesions. Am J Transplant 14, 272-283 (2014); published online EpubFeb (10.1111/ajt.12590).

51. M. Naito, U. Hainz, U. E. Burkhardt, B. Fu, D. Ahove, K. E. Stevenson, M. Rajasagi, B. Zhu, A. Alonso, E. Witten, K. Matsuoka, D. Neuberg, J. S. Duke-Cohan, C. J. Wu, G. J. Freeman, CD40L-Tri, a novel formulation of recombinant human CD40L that effectively activates B cells. Cancer Immunol Immunother 62, 347-357 (2013); published online EpubFeb (10.1007/s00262-012-1331-4).

52. A. Palanichamy, J. Barnard, B. Zheng, T. Owen, T. Quach, C. Wei, R. J. Looney, I. Sanz, J. H. Anolik, Novel human transitional B cell populations revealed by B cell depletion therapy. J Immunol 182, 5982-5993 (2009); published online EpubMay 15 (10.4049/jimmunol.0801859).

53. D. Pinna, D. Corti, D. Jarrossay, F. Sallusto, A. Lanzavecchia, Clonal dissection of the human memory B-cell repertoire following infection and vaccination. Eur J Immunol 39, 1260-1270 (2009); published online EpubMay (10.1002/eji.200839129).

54. M. Lucia, S. Luque, E. Crespo, E. Melilli, J. M. Cruzado, J. Martorell, M. Jarque, S. GilVernet, A. Manonelles, J. M. Grinyo, O. Bestard, Preformed circulating HLA-specific memory B cells predict high risk of humoral rejection in kidney transplantation. Kidney Int 88, 874-887 (2015); published online EpubOct (10.1038/ki.2015.205).

55. L. C. Borra, J. I. Roodnat, J. A. Kal, R. A. Mathot, W. Weimar, T. van Gelder, High within-patient variability in the clearance of tacrolimus is a risk factor for poor long-term 
outcome after kidney transplantation. Nephrol Dial Transplant 25, 2757-2763 (2010); published online EpubAug (10.1093/ndt/gfq096).

56. A. Lindholm, S. Henricsson, M. Lind, R. Dahlqvist, Intraindividual variability in the relative systemic availability of cyclosporin after oral dosing. Eur J Clin Pharmacol 34, 461-464 (1988).

57. N. Shuker, T. van Gelder, D. A. Hesselink, Intra-patient variability in tacrolimus exposure: causes, consequences for clinical management. Transplant Rev (Orlando) 29, 78-84 (2015); published online EpubApr (10.1016/j.trre.2015.01.002).

58. A. S. Levey, L. A. Stevens, C. H. Schmid, Y. L. Zhang, A. F. Castro, 3rd, H. I. Feldman, J. W. Kusek, P. Eggers, F. Van Lente, T. Greene, J. Coresh, E. P. I. Ckd, A new equation to estimate glomerular filtration rate. Ann Intern Med 150, 604-612 (2009); published online EpubMay 5 (10.7326/0003-4819-150-9-200905050-00006). 


\section{Acknowledgements:}

We thank Diana Metes, Camila Macedo, Bala Ramaswamy, and Beth Elinoff (University of Pittsburgh) for contributions to the execution of the study. We thank Rebecca Pike, Lyn Ambrose, and Sarita Workman (Royal Free Hospital, London UK) for contributions that enabled the performance of the external validation of the biomarker. We thank Gordon J. Freeman (Dana-Farber Cancer Institute) for kindly providing the hCD40L expressing 3T3 Cell line obtained through an MTA.

\section{Funding:}

Supported by grants from the Roche Organ Transplant Research Fund (2015-2016), American Society of Transplantation (2017-2019), NIH R34 AI136782 (all awarded to DMR) and National Institute for Health Research, UK (RCF2013/14-058, awarded to HS).

\section{Author Contributions:}

DMR conceived the study. DMR and AC designed the study. DMR, AC, AS, RB, FL and SH drafted the manuscript. DL is the study statistician. DMR, AC, DL, FL and SH analyzed and interpreted the data. AC, KM, CM and LZ conducted the experiments. AT, RM, SH, MH, AS and HS enrolled and followed up the patients. RM and HS managed clinical data. All authors were involved in reviewing the manuscript and approved the final version of the manuscript.

Declaration of interests: DMR serves on the scientific advisory board of Verici Dx. HS serves as a consultant for, and hold shares in Quell Therapeutics. HS hold shares in Kuur Therapeutics.

Data and materials availability: All data associated with this study are present in the paper or the Supplementary Materials. 


\section{Figure Legends:}

Figure 1. $T$ cell mediated rejection (TCMR) in the first post-transplant year and associated graft loss. (A) Flow diagram showing UPMC transplant recipients according to number of biopsies. (B) 330 of 596 patients in total underwent paired biopsies at both early (0-4 months) and late (5-12 months) timepoints in the first post-transplant year. The graphic depicts incidence of TCMR and its progression at early and late timepoints. (C) Five-year death-censored graft survival (GS) in the 330 patients with or without TCMR in the first post-transplant year. (D) Five-year death-censored GS in patient groups defined by the progression of TCMR in the first post-transplant year. (E) 5-year death-censored GS in patients with or without late TCMR. Survival analysis was by Kaplan Meier method and curves were compared by Log Rank tests. $* \mathrm{p}<0.001 ; * * \mathrm{p}=0.01$

Figure 2. Biomarker study flow diagram for the UPMC cohorts. Patients were enrolled from January 2013 through December 2015. Two surveillance biopsies were planned at 3 months (range: 2-4 months) and 12 months (range:11-14 months) along with any for-cause biopsies. Forcause biopsies were performed either for new onset proteinuria $>1 \mathrm{~g}$ or a $30 \%$ increase in serum creatinine from baseline. Patients with Banff >1B TCMR were subjected to a repeat biopsy 2 months after initiation of therapy. A total of 495 biopsies were performed in total (Training Set: 327; Internal Validation Set: 168). *4 patients excluded (3 rituximab treated and 1 with no viable cells)

Figure 3. Prediction of TCMR in Training and Internal Validation Sets. 
(A-D) ROC curves depicting ROC-AUC, and 95\% CI for the prediction of all TCMR (A), scTCMR (B), late TCMR (C), or de novo late TCMR (D) in the Training Set. (E-H) ROC curves for the Internal Validation Set for the prediction of all TCMR (E), scTCMR (F), late TCMR (G), or de novo late TCMR (H). Biomarker performance was tested at an optimal cut-off of 1.3 based on the Training Set. For calculating the ROC AUC, the data distribution was assumed to be nonparametric.

Figure 4. Risk stratification of patients based on their T1B IL-10/ TNF $\alpha$ ratio. (A) Patients in both the Training and Internal Validation Sets $(n=240)$ were combined and grouped based on the distribution of their T1B IL-10/ TNF $\alpha$ ratio. TCMR rates are shown for each group. Three risk categories were apparent. High-risk: T1B IL-10/TNF $\alpha$ ratio of 0-1.3 (red box: overall TCMR rate $83 \%$ ); Intermediate risk: T1B IL-10/TNF $\alpha$ ratio of 1.31-1.6 (gray box: TCMR rate 18\%); Low-risk: T1B IL-10/TNF $\alpha$ ratio greater than 1.6 (black box: overall TCMR rate $6.5 \%$ ). (B) 174 patients from this combined cohort with paired biopsies at both early and late timepoints were used to study the progression of TCMR in relation to the biomarker. Early TCMR: highrisk group, $60 \%$ vs. low-risk group 5\%; p<0.001. De novo late TCMR: high-risk group, 74\% vs. low-risk group, 5\%; $\mathrm{p}<0.001$. All late TCMR (both de novo and recurrent/recalcitrant): high-risk group, 58\% vs. low-risk group, 5\%; p<0.001. Groups were compared by Fisher's exact test.

Figure 5. Prediction of T Cell Mediated Rejection (TCMR) in the External Validation Set. The cut-off value of 1.3 determined in the Training Set was used to assess biomarker performance. (A) Prediction of any TCMR in the first post-transplant year. (B) Precision recall 
curve analyzing precision (PPV) vs. recall (sensitivity) for the T1B IL-10/TNF $\alpha$ ratio for any TCMR in the first year. (C) Prediction of late TCMR in the first post-transplant year. (D) Precision recall curve for late TCMR prediction by the T1B IL-10/TNF $\alpha$ ratio. For calculating the ROC AUC, the data distribution was assumed to be non-parametric.

Figure 6. Forest Plot of T1B IL-10/TNF $\alpha$ ratio, TCMR, and patient subgroups. Patients combined from all three study cohorts were stratified by key clinical variables. The odds for TCMR was determined for each subgroup using logistic regression. The Forest plot depicts Odds Ratios (OR) for TCMR for each integer unit increase in the T1B IL-10/TNF $\alpha$ ratio. The column to the right shows the ROC-AUC derived for the predictive ability of IL-10/TNF $\alpha$ ratio in each patient subgroup to identify TCMR in the first post-transplant year. Error bars represent 95\% CI for the odds ratios.

Figure 7. Association between T1B IL-10/TNF $\alpha$ ratio and long-term clinical outcomes. Patients in the combined Training and Internal Validation Sets (A, C, E, G) and in the External Validation Set $(\mathbf{B}, \mathbf{D}, \mathbf{F}, \mathbf{H})$ were divided into high-risk $(\leq 1.3)$ and low-risk groups $(>1.6)$ based on their T1B IL-10/TNF $\alpha$ ratio. eGFRs were compared using repeated measures modelling and Geisser-Greenhouse correction. (A) Mean eGFR values of high-risk versus low-risk patients in the combined Training and Internal Validation Sets (ml/min). ${ }^{\wedge} \mathrm{p}=0.005{ }^{\wedge} \wedge \mathrm{p}=0.003$. (B) Mean eGFR values of high-risk versus low-risk patients in the External Validation Set. \#p=0.02; $\# \# \mathrm{p}=0.008$; \#\#\#p=0.01. (C-D) Overall graft survival survival for the combined Training and Internal Validation Sets (C) and External Validation set (D). (E-F) Death censored graft survival for the combined Training and Internal Validation Sets (E) and External Validation set (F). (GH) Composite endpoint comprised of death, graft loss and impending graft loss 
(eGFR $<30 \mathrm{ml} / \mathrm{min}$ and decline in eGFR $>30 \%$ ) for the combined Training and Internal Validation

Sets $(\mathbf{G})$ and External Validation set $(\mathbf{H})$. Survival analysis was done by Kaplan Meier method and curves compared by Log Rank test.

\section{Figure 8. Effect of anti-TNF $\alpha$ on regulatory $B$ cell activity and in vitro plasmablast} differentiation. (A) PBMCs obtained at 3 months from low-risk $(n=4)$ and high-risk patients $(n=4)$ were subjected to B cell depletion or were left undepleted, followed by anti-CD3 stimulation. Within each patient group (high- and low-risk) the change in expression of each cytokine by $\mathrm{CD} 4^{+} \mathrm{T}$ cells after $\mathrm{B}$ cell depletion was compared to the baseline expression without $\mathrm{B}$ cell depletion. The percent change in $\mathrm{CD}^{+} \mathrm{T}$ cell cytokines with $\mathrm{B}$ cell depletion between low- and high-risk groups is depicted. (B) Analysis of the IL-10/TNF $\alpha$ ratio in total B cells and individual B cell subsets from healthy volunteers $(n=9)$ stimulated for 24 hours either in the presence of isotype control antibody or anti-TNFa antibody. (C) Analysis of the proportion of CD4 $\mathrm{T}$ cells producing IL-10 (left panel) and TNFa (right panel) following anti-CD3 stimulation. CD4 T cells were cultured alone or co-cultured with B cells in the presence of isotype control or anti-TNF $\alpha$ antibody ( $\mathrm{n}=4$ healthy volunteers). (D) B cell differentiation into plasmablasts (induced by culture with TLR7 agonist, R848, and recombinant human IL-2) in the presence of either isotype control or anti-TNFa antibody ( $\mathrm{n}=17$ patients 3 months posttransplant). (E) Comparison of the proportion of plasmablasts expressing IL-10 generated as in panel D. (F) Comparison of respective $\operatorname{IgG}$ sub-class concentration in the cell culture supernatants by plasmablasts generated as in panel D. Paired comparisons were analyzed by Wilcoxon Sign Rank test. Comparison of multiple groups was done by Kruskal Wallis test. Bars depict mean values with error bars representing SEM. 
